
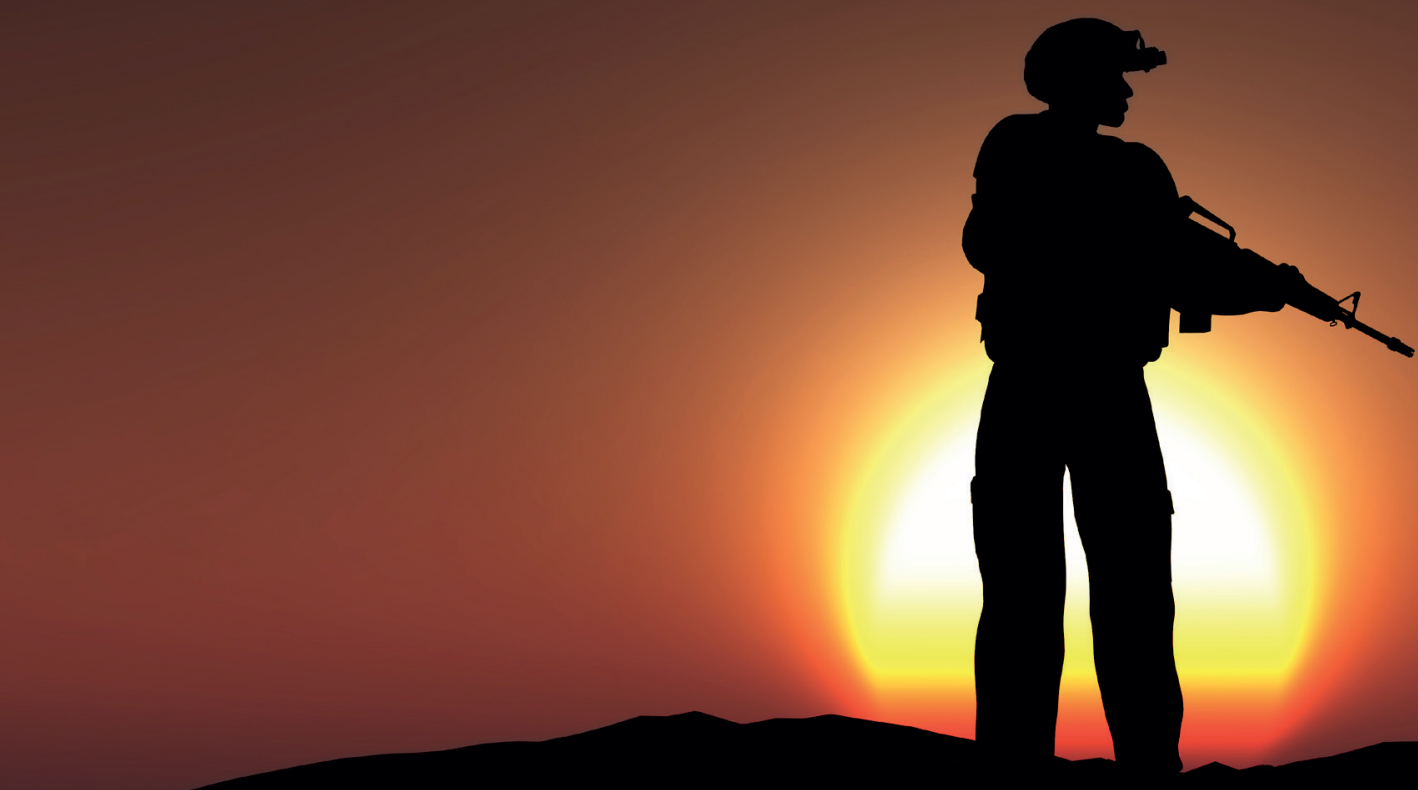

\title{
EL TRÁFICO ILEGAL DE ARMAS COMO UNA AMENAZA A LA SEGURIDAD INTEGRAL DEL ESTADO
}

Mayo. Mg. Ricardo J. Acuña Lopez ${ }^{1}$

\begin{abstract}
Resumen
El tráfico ilegal de armas ha constituido una amenaza para la seguridad integral del Estado Ecuatoriano, atribuyéndose como piedra angular a la forma de cómo las armas son adquiridas de manera ilegal a través de las fronteras de las provincias de Esmeraldas, Carchi y Sucumbíos. Fuerzas Armadas, como misión constitucional realiza acciones que llevan a neutralizar estas actividades dentro de un marco de la legalidad, equipamiento, entrenamiento e inteligencia; impidiendo los efectos asociados que se presentan por esta asimetría. Las estadísticas de armas incautadas durante el último quinquenio reflejan el incremento de esta actividad ilícita, muchas de ellas derivadas de los procesos de desarme, desmovilización y reintegración de excombatientes de las fuerzas irregulares de Colombia.
\end{abstract}

Palabras clave: amenaza asimétrica, seguridad del estado, tráfico, armas ilegales, capacidades

\section{Abstract}

The illegal arms trafficking has become a threat to the internal security of the Ecuadorian State, being attributed as a cornerstone to the way in which arms are acquired illegally across the borders of the Esmeraldas, Carchi and Sucumbíos provinces. The Ecuadorian Armed Forces, as part of its constitutional mission, carries out actions that lead to neutralize these activities within a framework of legality, equipment, training and intelligence; preventing the associated effects that are presented by this asymmetry. The statistics on weapons seized during the last five years reflect the increase in this illicit activity, many of them derived from the processes of disarmament, demobilization and reintegration of ex-combatants from the irregular forces in Colombia.

Keywords: asymmetric threat, internal security, trafficking, illegal weapons, training

\footnotetext{
${ }^{1}$ rikyacu@yahoo.com

Mayor de M.G. Ejército Ecuatoriano. MSc. Docencia Universitaria

ACADEMIA DE GUERRA DEL EJÉRCITO ECUATORIANO
} 


\section{Introducción}

T a seguridad de un Estado se apoya en su desarrollo y el progreso de sus conciudadanos para generar riqueza. Hoy en día estas visiones de impulso se ven muy amenazadas como consecuencia de las conocidas como nuevas amenazas ${ }^{1}$ que causan inestabilidad $\mathrm{y}$ desasosiego en la región. Estos son conflictos que mantienen desigualdades cuali-cuantitativas entre las fuerzas contendientes que desean mantener una ideología de poder como la narcoguerrilla, terrorismo, delincuencia organizada y su relación entre estos que, para demostrar su poderío, requieren de armas sofisticadas, las mismas que son adquiridas en un mercado de la ilegalidad. Estas circunstancias obligan a las fuerzas del orden a realizar acciones fuera de lo convencional, para mantener control interno y permitir el progreso de los Estados.

Bajo esta premisa, se realiza el presente trabajo con el objetivo de determinar las causas regionales que soportan al tráfico ilegal de armas y las acciones conexas que llevan al Estado ecuatoriano a ser un puerto de tránsito temporal por las amenazas vecinales y la gran permeabilidad de sus extensas fronteras de Esmeraldas, Carchi y Sucumbíos.

De manera inicial se refiere a las acciones regionales que conllevan al tráfico ilegal de armas y cómo estas son relacionadas con los fenómenos vecinales en la frontera norte, no se descuida la problemática de los grupos irregulares de Colombia y su asociación con el narcotráfico, muchas de estas actividades generan una necesidad alta para la adquisición de armas de confección nacional o extranjera.

Posteriormente, se determina la actuación de las Fuerzas Armadas mediante la revisión de la misión constitucional, las actividades que se desarrollan dentro de una política de defensa y las atribuciones en el mantenimiento de la seguridad interna del Estado. Finalmente, se define la instrucción y entrenamiento considerando el marco de la legalidad en apego estricto a los derechos humanos, a su vez una breve aplicación de normas de comportamiento que fortalecen la acción procedimental de las operaciones de control de armas municiones y explosivos.

Las fuentes consultadas en su mayoría han sido bibliográficas, también se realizó entrevistas a personas con gran conocimiento y experiencia en la temática, en forma general aportan concepciones de acciones que relacionan al tráfico ilegal de armas con amenazas conexas, especialmente las que dedican un análisis profundo en ésta temática, esto permite interrelacionar la problemática como un atentado a la seguridad interna

Nuevas amenazas (Asimétricas), todas aquellas condiciones de desestabilización, que se estructuran de una manera no convencional, aplicación de varias estratégicas, en escenarios diferentes, cuyo fin último es alimentar los intereses que pueden ser el debilitamiento del poder constituido, el tráfico ilegal de armas, terrorismo, narcotráfico, fundamentalismos religiosos, motines, disturbios, guerrillas, delincuencia común, crimen organizado etc. (Calatrava, 2002:25; Congreso Nacionala de Estudios de seguridad , Centro de Estudios y Análisis de Seguridad Universidad de Granada http://www.ugr.es/ ceas) de los estados que asciende a un fenómeno social local, regional y mundial.

\section{Consideraciones en la región para el tráfico de armas}

Los hechos del acontecer mundial y regional han convertido al Ecuador en un país de fácil acceso para desplazados y movilizados por la permeabilidad de nuestras fronteras, con mayor incidencia en las provincias de Sucumbíos, Carchi y Esmeraldas; los acontecimientos geopolíticos en la región lo han hecho proclive a enfrentar amenazas de manera desmesurada y no convencional para las fuerzas de seguridad, tales como el tráfico ilegal de armas, el crimen organizado y la delincuencia común, a estos efectos se generan fenómenos que afectan el progreso de la nación. El diario El Telégrafo (2018) hace una una redacción en la cual inidca que: “(...)dentro de los delitos más relevantes en la frontera norte se evidenció la tenencia de armas, por ejemplo, en Esmeraldas se registraron 141 casos, 35 en Sucumbíos y 12 en Carchi(...)" las cifras evidencian una frontera permeable propicia para realizar actos ilicitos de este modelo, con rutas estrategicamente planificadas en todo el territorio nacional.

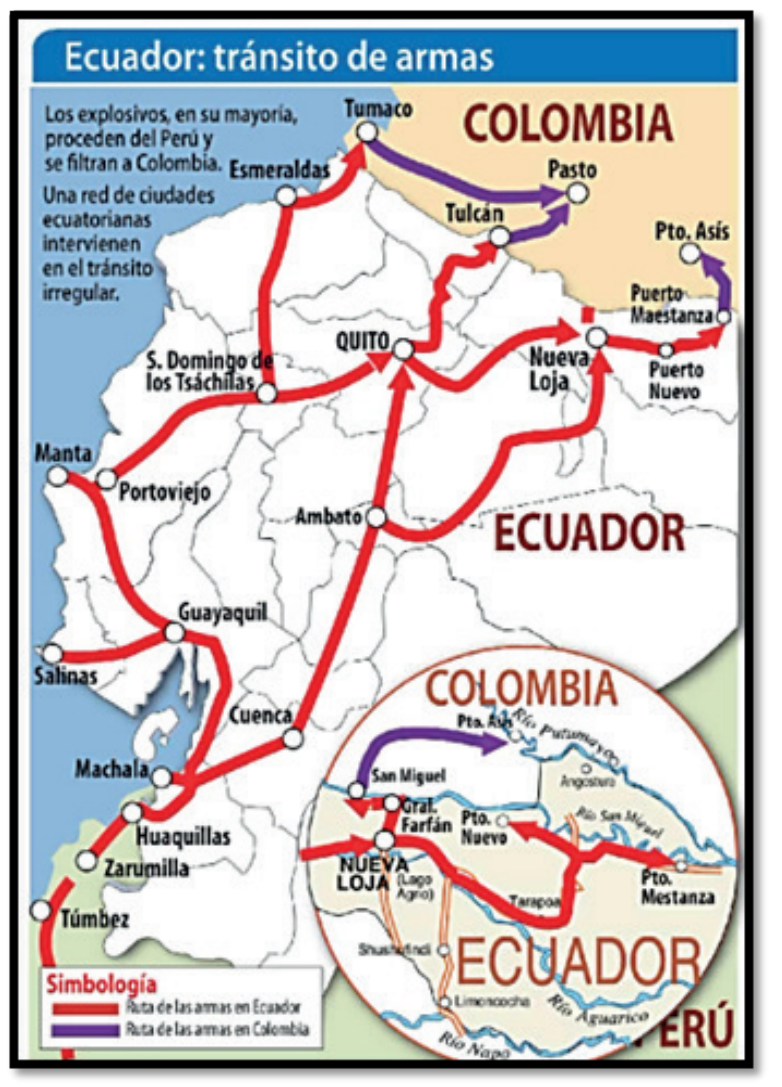

Figura 1. Ecuador: Tránsito de armas

Conviene subrayar que el proceso de desarme de las Fuerzas Revolucionarias de Colombia FARC establecen un foco de atención en el campo de la seguridad. En este caso, el tráfico ilegal de armas es el más detonante, lo que conlleva a configurar hipótesis de las nuevas amenazas 
para la seguridad como consecuencia del acontecer geopolítico de la región. Borja (2013) ya consideró en su análisis los efectos que estos ocacionan dentro de los paises vecinos: “(...) la confrontación que tiene lugar en el país debido a los fracasos en negociaciones previas y a la intersección cada vez más visible entre la lógica de la confrontación armada y el surgimiento del crimen organizado".

En este ámbito complejo de la protección fronteriza con Colombia ha demarcado para que el tráfico de armas, municiones y explosivos actúe bajo el dominio de la ilegalidad, creando un fenómeno complejo en la conexión con acciones delictivas; "por lo tanto se debe pensar que el tráfico de armas es un vínculo adicional entre el terrorismo y la delincuencia organizada que permiten a los grupos fuera de la ley a cometer actos ilícitos" (Celi F, Escalante, F. 2020).

Si consideramos que esta teoría se fortalezca, es probable que estos grupos antagónicos generen la necesidad del empleo de las armas de manera violenta para realizar sus actos de incidencia delictiva, por lo que cabe preguntarse: ¿dónde se adquieren éstas armas?. Ahora bién, definirlo genera un abanico de posibilidades que se deberían decifrar. De manera semejante coincide el Dr. Ramiro Díez señalando que: "Es posible que grupos aislados puedan dedicarse a esta actividad ilegal, a vender y traficar ilegalmente las armas, pero en consideración que; de manera lógica en el país debe existir quién esté dispuesto a comprarlas, es decir, ya se encuentra emprendido un mercado preliminar" (R. Díez. Entrevista telefónica, 22 de octubre del 2018).
Además, en su opinión hace hincapié que el trabajo de las Fuerzas Armadas debe ser exigente, puesto que las armas se trafican de todo el mundo sin que exista un control riguroso de las rutas que determina esta empresa bélica, desde su fabricación hasta su último destino, permitiendo un aprovechamiento del vacío existente dentro de la normativa legal; dejando aislados procedimientos que permitan realizar un monitoreo o seguimimiento acertado de la trazabilidad del comercio bélico.

Los reportes diarios de prensa que expresan un incontenible número de hechos delictivos con uso de armas, nos afirma que este mercado está vigente, puesto que hasta la fecha se manejan cifras preocupantes con base en la labor realizada por las instituciones encargadas de la seguridad del Estado entre Fuerzas Armadas y Policía Nacional; para poder referir existen cifras creciente en los últimos tres años, siendo el más preocupante este último por la incautación de armas en las operaciones militares de "Control de armas municiones y explosivos" (CAMEX). Lo notorio de todo esto es que en su mayoría son armas de calibre menor, las mismas que son de fácil manejo y fácil disimulación en los actos delictivos. Siendo achacable a que estos actos van conexos a otras amenazas como el micrótrafico, delincuencia común, sicariato, lucha de poder entre bandas delictivas, entre otros, que desiquilibran la tranquilidad y el desarrollo afinado del Estado.

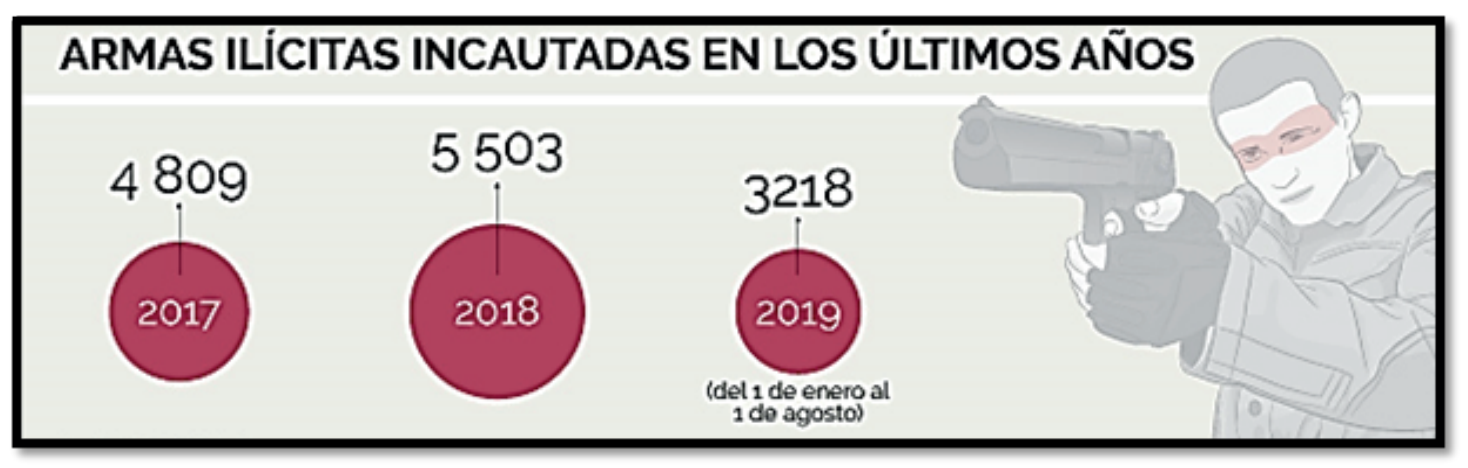

Figura 2. El silencioso tráfico de las armas en Ecuador Nota. Obtenido del Plan V Investigación.

Los números demuestran el mástil de un mercado que involucra de manera directa e indirecta en la conjugación de actividades de un negocio ilegal. En los últimos años se obtuvieron un total de 10850 armas de fuego ilegales producto de los decomisos, incautaciones y entregas voluntarias como resultados de las operaciones persuasivas en el país, de las cuales
6352 son armas tipo revolver, 2300 pistolas y 2198 cartucheras, además de 1669 accesorios y $15.7 \mathrm{~kg}$. de perdigones (SNCA; 2020) ${ }^{2}$ 


\section{TIPOS DE ARMAS QUE MÁS SE HAN DECOMISADO}

Desde enero 2017 a agosto 2019
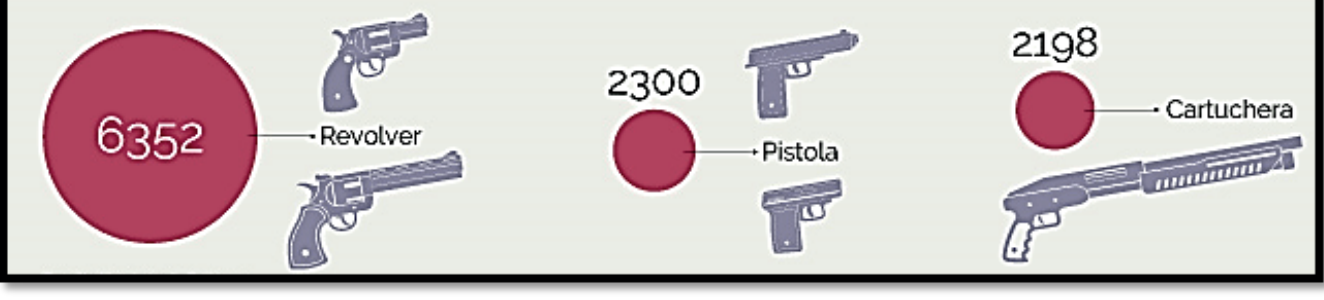

Figura 3. El silencioso tráfico de las armas en Ecuador

Nota. Obtenido del Plan V Investigación.

\section{Mecanismos de actuación en el tráfico ilegal de armas}

Los principales mecanismos empleados para traficar armas y municiones en el Ecuador, durante los últimos tiempos, se han considerado como los más comunes; los correos humanos, el camuflaje, los courier y la existencia de corrupción en los más altos niveles. Sin embargo, a su vez se ha detectado que las armas que se trafican en un mercado ilegal provienen principalmente de fabricantes artesanales y su comercialización filtrándose de arsenales como oficiales. Muchas de estas son disfrazadas en un marco de la legalidad dentro de las compañías de seguridad privada y de redes transnacionales por la evasión de permisos y registros que estos conllevan, por lo que se hace necesario conocer la actuación de estas actividades para neutralizar las acciones conexas.

\section{Tácticas, técnicas y procedimientos de la ilegalidad}

Reclutamiento: este mercado de armas, que genera inestabilidad a la seguridad integral, parte desde el reclutamiento, que no es más que la selección de sus miembros adeptos a estas organizaciones, elegidos con requisitos de sensibilidad, unos de manera voluntaria y otros incluso llegando a la intimidación por su condición social, condición económica, responsables de los almacenes, etc. Dentro de estos candidatos, estas organizaciones generalmente ponen su mira en lugares cercanos al cordón fronterizo, junto a centros de acopio, puertos, miembros de las Fuerzas Armadas, incluso empresas privadas y las más ligadas a las empresas de seguridad privada.

Obtención: la base de fortalecimiento de estas actividades es la obtención, generándose la piedra angular de este negocio ilegal para el tráfico de armas, munición y explosivos, es donde se generan los centros de acopio clandestinos a través de varios procedimientos que, muchos de ellos, se han determinado que son consumados a través del robo o hurto de empresas de seguridad públicas o privadas, nacionales o internacionales, compra de manera descontrolada en lugares de fabricación autorizados o importaciones a través de un mercado negro.
Movilización: se puede considerar como una segunda fase dentro de una estructura por la cual se movilizan las armas obtenidas de manera ilegal, desde el lugar de almacenamiento clandestino hasta los lugares de acopio que se administrarán para su comercialización. Los métodos que se han notado en estos tiempos utilizados por estas organizaciones es el denominado hormigueo, que consiste en la técnica de emplear miembros de la misma organización para trasladar de manera continua las armas causando la menor sospecha posible, algunos por medio de correos, encomiendas o trasportado por pasajeros y vehículos comunes. Los resultados obtenidos en este tipo de actividades también nos lleva a no descartar que esta movilización se la realiza a través de otros medios como; equipaje de pasajeros, contaminando cargas aérea, marítimas o terrestres.

Entrega: esta fase se puede representar por la comercialización en sí, es aquí donde se reciben los pedidos y se realizan las transacciones comerciales del material, todas las que han sido requeridas en el mercado nacional o internacional. Estos procedimientos han generado destrezas y habilidades económicas y con muy buenas estrategias de negociación, todo esto entrelazado en actos que comprometen acciones de ilegalidad, puesto que son actividades camufladas que atraviesan pasos ilegales fronterizos por rutas terrestres, y con gran ingenio, por rutas aéreas o fluviales.

\section{El tráfico ilegal de armas considerado como una nueva amenaza latente}

De acuerdo al documento Evaluación Estratégica 1998 hecho por la National Defense University, las técnicas asimétricas o amenazas asimétricas son una versión de "pelea sucia" o de "pelea no limpia" (not fighting fair), la que puede incluir el uso de la sorpresa en toda su dimensión estratégica y operacional y el empleo de las armas de manera no prevista o planificada por Estados Unidos. "No pelear limpio" también implica la posibilidad del enemigo de diseñar una estrategia que altere de manera fundamental el terreno en el que tiene lugar la lucha (NDU, 1998).

Albert Widmer (2004), se refiere a la Guerra Asimétrica como "el choque entre dos entidades que 
se distinguen fundamentalmente por una enorme disparidad de fuerzas con que disponen, y el empleo no convencional de las mismas, por una de ellas, para el logro de los objetivos en un conflicto".

El Libro de la Defensa Nacional de Chile define a las amenazas asimétricas como aquellas "que no se realizan por medios homólogos al Estado desafiado y que siendo sus ejecutores, por tanto, militarmente inferiores pueden inferirle grave daño. Lo propio de ellas es su alto nivel de impredictibilidad (sic)" (LDN, 2002, pág. 64).

La Política de la Defensa Nacional del Ecuador, considera amenazas globales, a aquellas de naturaleza distinta a las nuevas amenazas, preocupaciones y otros desafíos a la seguridad, apuntalando al tráfico de armas municiones y explosivos como una amenaza que asocia, el narcotráfico, tráfico de personas, tráfico ilícito de inmigrantes y el contrabando de mercancías (M.D.N; 2018, pág. 52).

Desde esta óptica conceptual es evidente que el tráfico ilegal de armas constituye para los Estados el segundo negocio ilícito más lucrativo a nivel global, que debe ser afrontada en forma unilateral por las fuerzas de seguridad con parámetros de actuación. El Estado se apoya en el desarrollo y el progreso de sus conciudadanos para generar riqueza, hoy en día estas visiones de impulso se ven muy amenazadas como consecuencia de las conocidas amenazas asimétricas ${ }^{3}$ que causan inestabilidad y desasosiego en la región, pues estos son conflictos que mantienen desigualdades cuali-cuantitativas entre las fuerzas contendientes y de una u otra manera obliga a las fuerzas del orden a realizar acciones fuera de lo convencional, afectando el orden constitutivo de los Estados.

Bianchini (2009), hace una recopilación de las amenazas que durante el tiempo han generado inestabilidad dentro de los estados, su referencia la realiza con los países latinoamericanos en relación a quienes pertenecen al Mercosur ${ }^{4}$, Centroamérica y el Caribe, observándose notablemente que el tráfico de armas es uno de los puntales asociados al cometimiento de un sinnúmero de actos ilegales, enlista las nuevas amenazas en un marco regional, denotándose en todas ellas que estas amenazas son emergentes en toda la región, derivadas de la posición estratégica por el dominio de las rutas marítimas del Pacífico y Atlántico que son ineludibles para estas asimetrías.

\begin{tabular}{|l|l|l|l||}
\hline \multicolumn{1}{|c|}{ MERCOSUR } & \multicolumn{1}{|c|}{ PAÍSES ANDINOS } & CENTROAMÉRICA & \multicolumn{1}{c|}{ CARIBE } \\
\hline Narcotráfico & Narcotráfico & Narcotráfico & Narcotráfico \\
\hline Terrorismo & Terrorismo & Crimen organizado & Terrorismo \\
\hline Tráfico de Armas & $\begin{array}{l}\text { Pobreza y Carencias } \\
\text { Sociales }\end{array}$ & Terrorismo & $\begin{array}{l}\text { Pobreza y Carencias } \\
\text { Sociales }\end{array}$ \\
\hline Crimen organizado & $\begin{array}{l}\text { Guerrillas y Grupos } \\
\text { Subversivos }\end{array}$ & Tráfico de Armas & $\begin{array}{l}\text { Medio Ambiente } \\
\text { Desastres Naturales }\end{array}$ \\
\hline $\begin{array}{l}\text { Medio Ambiente } \\
\text { Desastres Naturales }\end{array}$ & Tráfico de Armas & $\begin{array}{l}\text { Pobreza y Carencias } \\
\text { Sociales }\end{array}$ & Tráfico de Armas \\
\hline $\begin{array}{l}\text { Pobreza y Carencias } \\
\text { Sociales }\end{array}$ & Crimen organizado & $\begin{array}{l}\text { Medio Ambiente } \\
\text { Desastres Naturales }\end{array}$ & Crimen organizado \\
\hline $\begin{array}{l}\text { Guerrillas y Grupos } \\
\text { Subversivos }\end{array}$ & $\begin{array}{l}\text { Medio Ambiente } \\
\text { Desastres Naturales }\end{array}$ & $\begin{array}{l}\text { Guerrillas y Grupos } \\
\text { Subversivos }\end{array}$ & \\
\hline
\end{tabular}

Figura 4. Materialización de las amenazas emergentes, en las regiones Nota. Bachini, L. V. (2009:93). Revista Estrategia, 94.

La preocupación de nuevas amenazas o de mutación de las amenazas no es nueva, esto se lo había anunciado ya desde la década pasada, conocida como; las nuevas amenazas del siglo XXI; la $\mathrm{ONU}^{5}$, en su planteamiento de la "Seguridad Colectiva" eleva un informe en el 2005, conocido como "Un mundo más seguro, la seguridad que compartimos", donde cada uno de los actores participantes proponen sus planteamientos para que cada estado proponga estrategias de seguridad afines a sofocar estos espantajos de manera eficiente y efectiva con gobernanza y total soberanía. Así mismo alerta que son consideradas amenazas a la seguridad internacional: "procesos que cause muerte a gran escala o una reducción masiva de las posibilidades de vida

\footnotetext{
${ }^{3}$ Amenazas Asimétricas, todas aquellas condiciones de desestabilización, que se estructuran de una manera no convencional, aplicación de varias estratégicas , en escenarios diferentes, cuyo fin último es alimentar los intereses comunes , que pueden ser el debilitamiento del poder constituido, el tráfico ilegal de armas, terrorismo, narcotráfico, fundamentalismos religiosos, motines, disturbios, guerrillas, delincuencia común, crimen organizado etc. (Calatrava, 2002:25; Congreso Nacionala de Estudios de seguridad, Centro de Estudios y Análisis de Seguridad Universidad de Granada http://www.ugr.es/ ceas)

${ }^{4}$ MERCOSUR: El Mercado Común del Sur, es un proceso de integración regional instituido inicialmente por Argentina, Brasil, Paraguay y Uruguay al cual en fases posteriores se han incorporado Venezuela y Bolivia, ésta última en proceso de adhesión. Cuyo objetivo principal es, propiciar un espacio común que generara oportunidades comerciales y de inversiones a través de la integración competitiva de las economías nacionales al mercado internacional. (MERCOSUR, 2018; https://www.mercosur.int/)

${ }^{5}$ ONU: La Organización de las Naciones Unidas es la mayor organización internacional existente. Se creó para mantener la paz y seguridad internacionales, fomentar relaciones de amistad entre las naciones, lograr la cooperación internacional para solucionar problemas globales y servir de centro que armonice las acciones de las naciones.
} 
y que socave el papel del estado". Definiéndose los siguientes seis grupos:

- Las amenazas, económicas y sociales como la pobreza etc.

- Los conflictos entre los Estados.

- Los conflictos internos, como la guerra civil y el genocidio.

- El uso de armas nucleares, químicas, radiológicas o biológicas.

- $\quad$ El terrorismo y

- Delincuencia organizada transnacional.

Por lo tanto, todas estas amenazas exigirán un cuerpo armado clandestino con una imposición violenta de su fuerza a través del uso indebido de las armas, las mismas que su negociación está dentro de un mercado negro que es imparable y dificultoso para mantener el control de su circulación, por lo que se hace imprescindible la atención del abasto de éste tráfico ilegal que permita generar planes minuciosos para neutralizar las amenazas. Aguirre K (2011) acentúa que estos abastos podrían ser: (...)excedentes de armas de conflictos armados (interno o externos); robos o desvíos de armas de arsenales oficiales del país o de otros países; filtraciones desde empresas de seguridad privada; armas compradas legalmente con licencias falsificadas que luego pasan a hacer pate de grupos criminales; armas que se han fabricado de manera cacera, artesanal e ilegal; armas adquiridas legalmente en el país pero que tienen permisos de porte o tenencia vencidos(...)

Así mismo, atribuye que en el contexto regional el origen de las armas ilegales, específicamente de Colombia: "pueden provenir de stocks de grupos armados que se han sometido a procesos de $\mathrm{DDR}^{6}$ en el país, pero cuyo desarme ha sido incompleto". En el caso de Ecuador, esos reincidentes han buscado refugio en espacios de las poblaciones con un stock de armas disponibles que son el punto de partida para conocer la dinámica del tráfico de armas interno desde su origen, análisis de rutas y medios utilizados con el fin de mantener un destino final de uso.

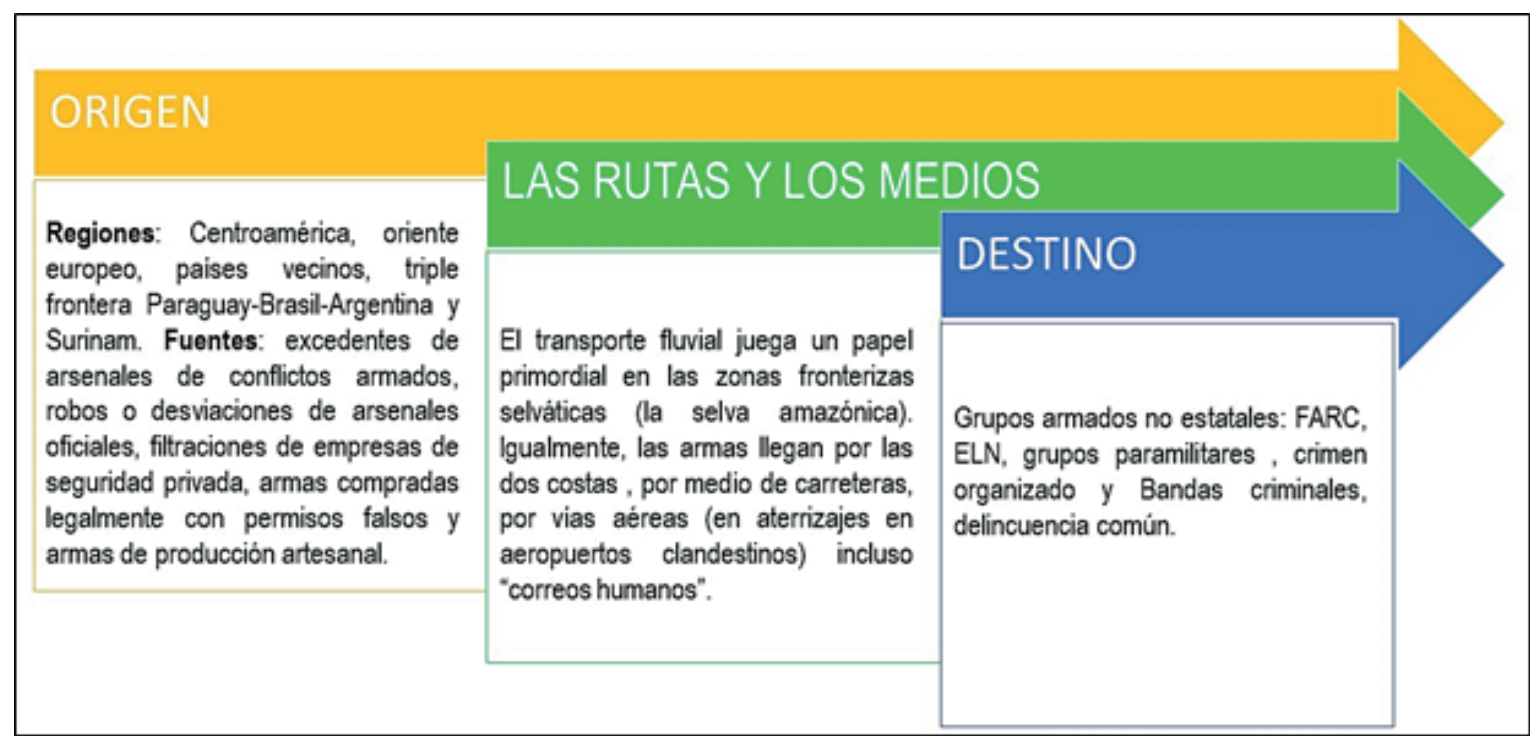

Figura 5. Orígenes, rutas y destinos de las armas

Todo esto abre un abanico de posibilidades que permitirán a las fuerzas del orden generar la mejor planificación para contrarrestar los orígenes de un mercado negro que genera zozobra en la región, donde el Ecuador se convierte en un puerto temporal de entrada y salida para estos negocios ilícitos.

\section{El Ejército y su preparación para neutralizar el tráfico ilegal de armas}

La Constitución en su Art. $158^{7}$ pone en manifiesto como misión fundamental a Fuerzas Armadas, brindar el apoyo en la seguridad integral del estado sin inhibir o perturbar las acciones de la Polícia Nacional; dentro del Art. 3 se establecen los deberes del Estado y determina la obligación de garantizar la Seguridad
Integral a los ciudadanos como parte de las misiones constitucionales a las Fuerzas Armadas, así mismo, la Ley de Seguridad Pública y del Estado permite las coordinaciones institucionales ejerciendo gobernanza para crear las mejores condiciones de seguridad y paz para la nación. Por otra parte, las misiones subsidiarias permiten que Fuerzas Armadas realicen operaciones en la defensa interna y seguridad del territorio nacional,

\footnotetext{
${ }^{6}$ DDR: Es la sigla que identifica los procesos de desarme, desmovilización y reintegración de excombatientes. (IEGAP, 2013. Desarme, Desmovilización Y Reintegración: Una Introducción Para Colombia Cuaderno de Análisis $\mathrm{N}^{\circ}$ 01/13.Universidad Militar Nueva Granada).

${ }^{7}$ La Constitución de la República (2010), "Las Fuerzas Armadas Tienen como misión fundamental la defensa de la soberanía y la integridad territorial. La protección interna y el mantenimiento del orden público son funciones privativas del Estado y responsabilidad de la Policía Nacional."
} 
tales como: las tareas de control de armas municiones y explosivos para restringir el tráfico y la tenencia ilegal, señalando la importancia de las consecuencias que este delito genera, obstaculizando el desarrollo social y económico de los países.

$\mathrm{Si}$ bien es cierto, la seguridad interna es responsabilidad exclusiva de la Policía Nacional, también es incuestionable el rol que Fuerzas Armadas desempeña, en especial en las zonas fronterizas como medida preventiva para sofocar el caldo de cultivo de las amenazas:

Delitos como el secuestro, la extorsión, el hurto en sus diferentes modalidades y el homicidio en las zonas urbanas, van en aumento y se encuentran íntimamente ligados al tráfico y porte ilegal de armas, en especial porque la delincuencia común que delinque para el crimen organizado, mantiene independencia para hacer frente a este tipo de actividades (...) (Ardila 2015, pág. 20).

Ahora bien, las operaciones del control de armas se mantienen en forma permanente. Sin embargo, cabe la pregunta ¿la preparación del personal militar es el adecuado? El soldado del nuevo milenio debe considerar un entrenamiento que afronte los escenarios de manera prospectiva, puesto que las nuevas amenazas son sigilosas. La seguridad ha dejado de ser convencional y el traficante desarrolla tácticas y técnicas renovadas que exige a la vez, nuevos sistemas que permitan descifrar su modus operandi. Es así que para cumplir con estas tareas de eliminar estas amenazas asimétricas, necesariamente deben articularse factores como la preparación y entrenamiento, un marco jurídico específico, el equipamiento apropiado y el presupuesto necesario que cubra todas estas insuficiencias.

Dicho lo anterior; Eduardo Vaca Rodas coincide diciendo: “(...) la capacidad de las Fuerzas Armadas se sustenta en la instrucción-entrenamiento, en la organización y en el equipamiento, incluyendo la tecnología" (Crnl. E.M.C. (S.P) E.Vaca.Entrevista.29 de octubre del 2018). Así, es menester estructurar un marco doctrinario que contenga todos los procedimientos de actuación para cada escenario, en los cuales se reflejen las competencias ${ }^{8}$ específicas a ser adquiridas; proponiendo contenidos que recalquen la importancia del uso progresivo de la fuerza y el respeto a la dignidad humana, puesto que: "La complejidad del escenario de combate en un conflicto asimétrico limita la aplicación de los principios generales del DIH, forzando a que los medios y métodos de combate permitidos sean cada vez más limitados" (Rodriguez, 2014, pág. 195).

Las Fuerzas Armadas deben determinar una estructura de instrucción y entrenamiento específica para enfrentar este tipo de amenazas. Lo primero es desarrollar un sistema de inteligencia especifico, que permitan visualizar de manera efectiva las tácticas, técnicas y procedimientos de la forma de actuación de estas organizaciones. Esto permitirá que todas las formas de instrucción y entrenamiento mejoren durante la ejecución con equipos necesarios que se dispongan o puedan ser mejorados y se adapten tácticas para enfrentar la amenaza, por ejemplo: técnicas de combate urbano, técnicas de patrulla de reconocimiento y de combate, tácticas de evaluación del escenario y magnitud de la amenaza, se considere además técnicas para una incursión, emboscada, etc. Sin lugar a duda, se aseveraría que lo esencial, sin lo cual no se podría tener éxito en la neutralización de este tipo de asimetría, es la actuación de elementos de inteligencia, mediante la aplicación de procedimientos efectivos y eficaces, entrega de una información precisa y oportuna del modus operandi de quienes se dedican al tráfico ilegal de armas, municiones y explosivos, esto admitirá un escenario de actuación exitoso de las Fuerzas Armadas con agilidad y certeza. En definitiva: "La doctrina debe preocuparse fundamentalmente para enfrentar las amenazas emergentes, mediante la potenciación de los sistemas de inteligencia; posterior las formas de empleo, organización y equipamiento se van adaptando acorde a las necesidades para neutralizar todo tipo de amenazas" (Crnl. E.M.C. (S.P) E.Vaca. Entrevista 29 de octubre del 2018). En este afán, el Ejército Ecuatoriano emprendió a partir del año 2019 de manera ambiciosa un proceso de transformación ${ }^{9}$ que permitirá en gran medida mejorar el actual modelo de instrucción y entrenamiento acoplando modernas metodologías que permitan incrementar el alistamiento operacional de las unidades para hacer frente a los escenarios actuales y futuros, esto está sujeto con el sostenimiento institucional y un bajo impacto aprovechando el ingenio y la creatividad del instructor.

Otro factor preponderante es el equipamiento para la ejecución de este tipo de operaciones. La seguridad integral a determinado a las Fuerzas Armadas en las operaciones de apoyo a las instituciones del estado y operaciones que alteran el ámbito interno, específicamente a las operaciones de control de armas, cuyo concepto es: emplear las unidades militares para ejecutar operaciones militares de control del porte y tenencia de armas, en todo o parte del territorio nacional, estas son ejecutadas bajo la denominación de operaciones CAMEX, y que por su naturaleza, este empleo debe estar acorde al escenario con el uso de armamento no letal, antimotines y de corto alcance que permitan a los miembros uniformados mantener el control en este tipo de sistematizaciones para accionar acorde a la legalidad vigente, dentro del marco regulatorio de actuación en el uso progresivo de la fuerza y sus respectivas normas de comportamiento.

\footnotetext{
8 "Para el Modelo Educativo, el eje principal de las concepciones pedagógicas y andrológicas son las competencias, donde el desempeño es entendido como uso, manejo o aplicación que el militar debe hacer de lo que sabe y no de conocimientos aislados" (DIEDMIL,2012).

9 "El proceso de transformación; permite proyectar al Ejercito para que sea una institución capaz de responder a varias capacidades, roles y misiones, preparándose y entrenándose para alcanzar la paz y el desarrollo del país", (DEFENSA.COM, 2015).
} 


\section{Marco legal de actuación}

El actuar de las Fuerzas Armadas, en el cumplimiento de sus misiones, requiere de una normativa legal acorde a los escenarios que se presenten, que aborde lo sensible de toda operación a cargo del personal militar. La institución armada como tal ha sido un referente del respeto y observancia de los procedimientos adecuados que, al tiempo de asegurar los resultados esperados, precautelan los derechos de las personas y los bienes que se hallen en juego. Desde esta comprensión, sus intervenciones deben considerar la responsabilidad integral tanto sobre los fines como los medios empleados.

Una de las consideraciones en este marco legal, es la Ley de fabricación, importación, exportación, comercialización y tenencia de armas, municiones, explosivos y accesorios con la expedición de su respectivo reglamento que permite su regulación específicamente en su Art. 9: "Las armas de fuego, municiones, explosivos y accesorios, para el uso del Estado, Instituciones bancarias y empresas de seguridad privada, adquirirán previa autorización otorgada por el Ministerio de Defensa Nacional (...)" y aclara que: "Las armas autorizadas, de uso civil o particular se adquirirán previo el permiso otorgado por el Jefe del Estado Mayor del Comando Conjunto (...)", lo que hace que muchas de las armas de confección artesanal y de un mercado ilegal circulen eludiendo los controles de los miembros de las Fuerzas Armadas, permitiendo el comienzo de una violencia armada que limita el desarrollo armónico el país.

En sí, el Derecho Operacional aplicado hoy en día, ha permitido orientar las actuaciones de los miembros de las Fuerzas Armadas dentro de la legalidad considerando que : “(...) frente a las amenazas y factores de riesgos derivados de la delincuencia organizada, las Fuerzas Armadas han tenido que actuar con energía y decisión, haciendo un uso progresivo de la fuerza con la participación de un asesor de derecho en sus operaciones militares, a fin de no incurrir en violaciones de los Derechos Humanos” (MDN, 2014).

\section{Empleo del Uso Progresivo de la Fuerza}

El contacto del personal militar con la población civil en estos casos es muy vulnerable, puesto que al tratarse de una asimetría, se ocultan con gran habilidad para el cometimientos de actos, en el acopio, transporte y comercialización de armas y municiones de manera ilegal, por lo que es de necesidad urgente que todos los miembros que conducen estas operaciones conozcan de manera procedimental, el cómo actuar bajo un uso progresivo de la fuerza, que en definitiva se impone desde la presencia militar hasta el uso de la fuerza letal, en legítima defensa bajo los principios de proporcionalidad y racionalidad.

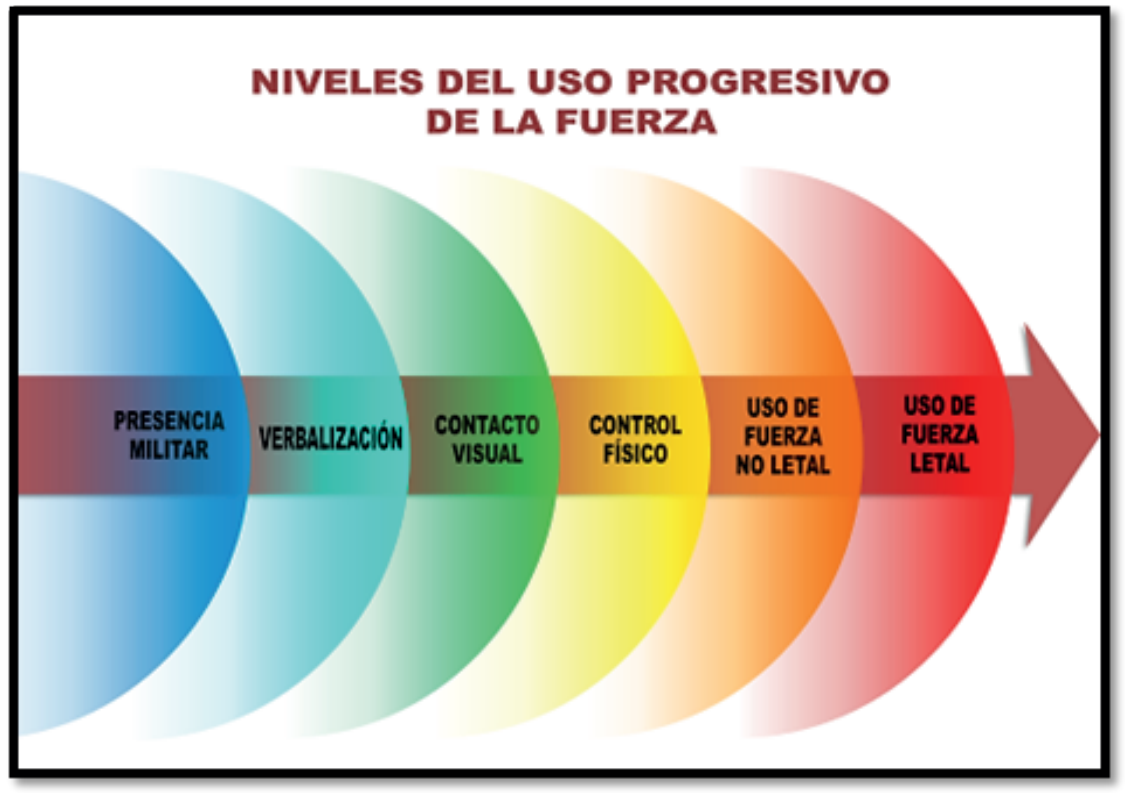

Figura 6. Niveles del uso progresivo de la fuerza

(...) este uso de la fuerza inicia cuando este control pacífico y preventivo, se ve vulnerado por enfrentamientos, siendo este el momento oportuno para analizar cuáles son los mecanismos o las actuaciones que se debe llevar a cabo para evitar cualquier tipo de vulneración de Derechos Humanos. Esto con el fin, no solamente de precautelar la seguridad ciudadana, y garantizar el actuar profesional y adecuado de los miembros de seguridad, lo cual es labor principal del Estado, sino también para garantizar que los miembros de seguridad, cuenten con los medios suficientes para actuar y precautelar tanto su integridad como la de la ciudadanía (Torres, 2014, pág. 50). 


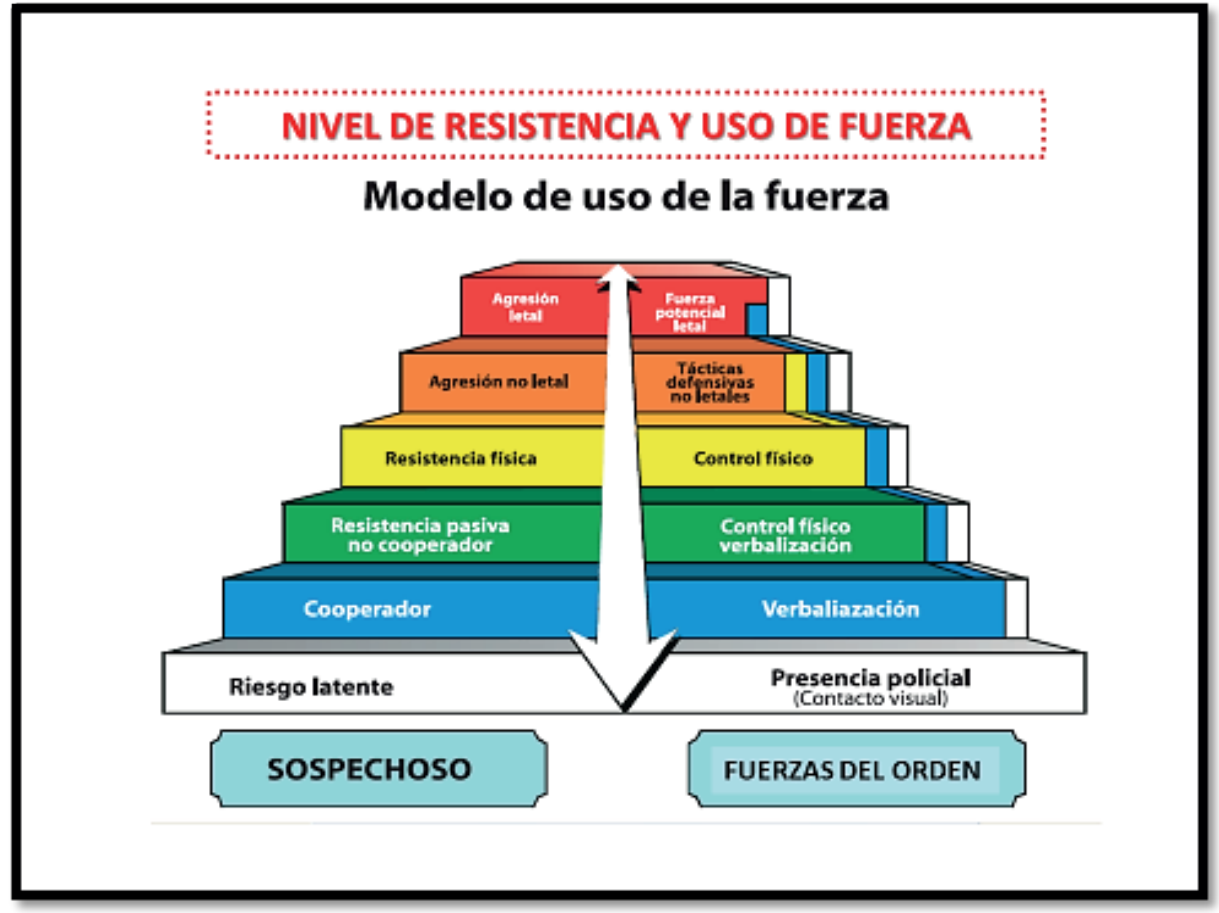

Figura 7. Niveles de resistencia y uso de la fuerza

\section{Aplicación de normas de comportamiento}

Las normas de comportamiento han constituido un conjunto de medidas que establecen los procedimientos a ser aplicados por los miembros de la fuerza pública para el empleo de la fuerza y uso de las armas de fuego; enmarcando parámetros dentro de los cuales el personal militar está obligado a normalizar su actuación, evitando cometer excesos que quebranten las leyes y aún más, lleguen a instituir una violación de los DD.HH. Esto permite garantizar el derecho natural a la legítima defensa, la protección de la población y de los bienes.

Se hace imperativo que dentro de la planificación de las operaciones militares, en especial en el control de armas municiones y explosivos, exista la consideración para que los comandantes y autoridades competentes detallen estas normas de comportamiento como un medio que permitan fiscalizar el uso de la fuerza, de ser el caso, con base en las reglas que permitan el enfrentamiento perfilado a un actuar concienzudo bajo la consideración de las condiciones y el ambiente que pudiesen presentarse este $\mathrm{u}$ otro tipo de amenazas (caseríos, presuntos laboratorios, vehículos terrestres, medios aéreos, marítimos y fluviales para tráfico ilícito, entre otros). Por lo que es pertinente que cada uno de los miembros planificadores, en el área de su competencia y de acuerdo a la especificidad, desarrollen un instrumento de normas de comportamiento, apegado a la legalidad del derecho que se aplica a las operaciones militares. Cabe resaltar que esto conlleva a determinar varias necesidades adicionales que es imposible descuidarlo; como la provisión del debido equipamiento a ser empleado, admitiendo a identificar y contrarrestar las amenazas (binoculares, visores nocturnos, visores térmicos, sensores, etc.), todo esto, para advertir una intervención inicial antes del empleo de la fuerza (megáfonos, parlantes tácticos, bengalas, etc.).

Es recomendable que dentro de las normas de comportamiento, entre otras, se considere lo siguiente:

- Se permita el uso de la fuerza hasta emplear el arma de fuego con el único fin de proteger la propiedad de la unidad en legítima defensa, exclusivamente cuando se ponga en riesgo real e inminente la vida de los miembros.

- Considerar que el personal aprehendido sea entregado al personal policial dentro de las 24 horas subsiguientes y puesto en conocimiento de un fiscal para los trámites respectivos.

- La custodia de los bienes y medios decomisados, obligatoriamente deben ser acto procedimental de la Policía Judicial, por lo que se dispondrá que pasen a órdenes de la Fiscalía dentro de las 24 horas subsiguientes.

- Es necesario que cada miembro de las Fuerzas Armadas, en este tipo de misiones, deberá identificarse como parte del protocolo.

- La conformación de los equipos a emplearse necesariamente deberán estar integrados por al menos con un militar de género femenino.

- Para la revisión del equipaje (maletas, bolsos, carteras, mochilas), el personal militar deberá de manera necesaria, revisarla en presencia del propietario de dicho equipaje.

- En caso de encontrarse armas deberá requerirse la presentación del permiso original correspondiente, 
de carecer de esto, será considerado como una arma ilegal, será decomisada y su propietario puesto a órdenes de la justicia.

Todas estas normas de comportamiento, para que las operaciones puedan adoptar procedimientos de actuación, deben deferir a mitigar o neutralizar la acción de muchos actos ilegales y entre estos a contrarrestar el tráfico ilegal de armas, municiones y explosivos, específicamente con la intencionalidad que estos cuerpos ilegales lo realizan como limitando sus rutas de transporte, terminando el hormigueo ${ }^{10}$ y el mercado clandestino.

Por así mencionarlo, en el caso de peatones, el personal militar deberá identificarse, comunicar que se encuentra realizando una operación del control de armas, donde se requerirá al ciudadano que le autorice y permita el chequeo o registro físico para la verificación del posible ocultamiento de armas de manera ilegal. Si fuese el caso de vehículos particulares; dentro su actuar se deberá además del registro físico considerar precisión en los equipajes de los ocupantes. Todas estas acciones deben estar enmarcadas en el apego estricto al respeto y aplicación de las normativas legales que cobijan a los miembros de la fuerza pública.

\section{Conclusiones}

Las nuevas amenazas a la seguridad del Estado están latentes en el Ecuador; el tráfico ilegal de armas es el puntal para el fortalecimiento de actos de violencia dando origen al crimen organizado, delincuencia común, sicariato e incluso para seguridad de minería ilegal e intereses de grupos opuestos. "Este delito genera inseguridad, obstaculiza el desarrollo social y económico de los países por la pérdida de vidas humanas y de recursos materiales en cuanto a infraestructura, contribuye al fortalecimiento de grupos al margen de la ley, origina permanente violación de los derechos humanos y por lo tanto, afecta la estabilidad de los Estados" (Ardila, 2015, pág. 49).

El uso de armas de fuego con fines delictivos no solo representa una amenaza para la seguridad de los ciudadanos de cualquier país, sino que también supone un peligro más amplio para la seguridad pública, el derecho a vivir en paz, la estabilidad y el desarrollo socio económico de los pueblos. Las armas de fuego demandan una gran riqueza en un mercado ilegal, por las técnicas fáciles de ocultar y transportar, involucrando varios actores que permiten su clandestinidad, generando grandes beneficios a los malhechores que trafican con ellas. La sociedad ecuatoriana mantiene como premisa que el aumento de estas actividades se responsabiliza al postconflicto colombiano, debido a la aparición de grupos delincuenciales y demás actos conexos, específicamente en los territorios fronterizos

\footnotetext{
${ }^{10}$ Hormigueo: técnica de emplear miembros de la misma organización para trasladar de manera continua las armas a menor escala, causando la menor sospecha posible, algunos por medio de correos, encomiendas o trasportado por pasajeros y otros camuflados en vehículos comunes.
}

de la provincias de Sucumbíos, Carchi y Esmeraldas, donde se hace necesario la actuación de instituciones que actúen con gobernanza e impulsen la integración de capacidad humana, técnica y tecnológica para acrecentar estrategias conjuntas con el Estado Ecuatoriano respaldado con la cooperación internacional y una normatividad penal drástica.

Las Fuerzas Armadas, hasta el momento, carecen de un marco doctrinario y sustento legal óptimo, que permita debilitar las nuevas amenazas a la seguridad integral, por lo que se debe estructurar planteamientos de tácticas y técnicas vinculadas con un marco jurídico, con conocimiento del trato a la dignidad de las personas, empleo progresivo de la fuerza, normas claras de actuación, aplicación de operaciones de inteligencia y contrainteligencia, empleo de armamento y equipo versátil, instrucción y entrenamiento acorde a los nuevos escenarios planteados con un cuerpo doctrinario que permita afrontar estas amenazas. Al respecto, Calatrava (2002, pág. 6) indica: “(...) el mundo experimenta un aumento de guerras a las que se bautiza con nuevos nombres (limitadas, de guerrillas, camufladas, sin restricción, asimétricas, etc.) y en las que aparecen variados niveles de violencia." Por lo tanto, el personal militar debe explotar sus habilidades para resguardar la integridad territorial y la soberanía nacional. Es sostenible que la responsabilidad de la seguridad integral es una vinculación de uniformados, gobierno y civiles y que para realizar mejoras en procedimientos es necesario que los actores comprometidos generen los presupuestos necesarios para la implementación de un plan sincronizado que satisfaga las condiciones de seguridad integral del país.

\section{Referencias}

Aguirre T.K. (2009). El tráfico de armas en Colombia: una revisión desde los orígenes a los destinos. Revista Latinoamericana de Seguridad Ciudadana. Ecuador.

Ardila, C. A. (2015). Tendencias y consecuencias del tráfico ilegal de armas en el Ecuador, frente a un post conflicto en Colombia. Trabajo de investigación, para obtar el título de profesional en relaciones internacionales y estudios políticos. Bogota.

Bachini, L. V. (2009). Amenazas actuales a la seguridad regional y continental. Revista Estrategia, 94. Montevideo

Borja, S. (2013). Escenarios posibles frente al proceso de paz colombiano. Efectos internos y regionales. FES. SEGURIDAD, 6. doi:www.fes-seguridadregional. org

Calatrava, A. C. (2002). Congreso Nacional de Estudios de Seguridad. El Conflicto Asimétrico. Universidad de Granada. http://www.ugr.es/ ceas

Celi F,Escalante F( 2020). Nuevas amenazas para el Ecuador en la frontera. Revista Academia de Guerra del Ejército Ecuatoriano, 13 (1).Ecuador. 
DIEDMIL. (2012). Modelo Educativo de las Fuerzas Armadas. C.E.D.E.

DTDM, (2020).Línea de transformación de instrucción $y$ entrenamiento. Ecuador.

Figueroa, E. A. (2015). Tendencias y consecuencias del tráfico ilegal de armas en ecuador, frente a un postconflicto en Colombia. http://hdl.handle. net/10654/13910.

Geiss, R. (2006). Las estructuras de los conflictos asimétricos. Internacional Revieu of thre red cross. 23. https.www.icrc.orgspaassetsfilesotherirrc_864_ geiss.

La Hora, E (Agosto de 2013).Entre Ecuador y Colombia hay 125 pasos pronterizos. pág. *.Obtenido de https:// lahora.com.ec/noticia/1101547157/entre-ecuadory-colombia-hay-125-pasos-fronterizos-clandestinos

L.D.C. (2002). Libro de la Defensa Nacional de Chile. Chile.

Ministerio de Defensa Nacional. (2009). "Ley de fabricación, importación, exportación, comercialización y tenencia de armas, municiones, explosivos y accesorios". Ecuador.

Ministerio de Defensa Nacional. (2015). "Reglamento a la ley de fabricación, importación, exportación, comercialización y tenencia de armas, municiones, explosivos y accesorios". Ecuador.

Ministerio de Defensa Nacional. (2018). La Política de la Defensa Nacional del Ecuador "Libro Blanco". Ecuador.

Ministerio de Defensa Nacional. (2014). Ministerio de Defensa Nacional del Ecuador "Manual de Derecho Operacional". Ecuador.

Nafra, M. (2020). La legítima defensa en el actuar policial. Tesis doctoral. Argentina .

NDU. (1998). National Defense University. Evaluación Estratégica 1998. Estados Unidos.

Ocampo, A. B. (2002). La era de los conflictos Asimétricos. Revista Review.

PlanV (2019). El silencioso trafico de armas en Ecuador. https://www.planv.com.ec/investigacion/ investigacion/el-silencioso-trafico-armas-ecuador

Rodriguez, K. A. (2014). Aplicabilidad de principios fundamentales del Derecho Internacional Humanitario, a la conducción de las hostilidades en los conflictos armados asimétricos. Disertación previa a la obtención del título de abogada. Quito, Ecuador. http: repositorio.puce.edu. ecbitstreamhandle/22000702113.J01.001727/ pdfsequence/ $4 \&$ isAllowed=y.pdf

Telegrafo, E. (2015). La tenencia de armas, el delito mas relevante en la frontera norte. http://www. eltelegrafo.com.ec/noticias/justicia/1/ la-tenenciade-armas-el-delito-mas-relevante-en-la-fronteranorte

Torres, A. (2014). Derechos humanos de las fuerzas de seguridad del estado en las protestas sociales del ecuador: análisis jurídico desde el uso progresivo de la fuerza. Universidad Católica. Ecuador 